\title{
Sualtı Kablosuz Algılayıcı Ağlarda Aloha tabanlı Maliyet Etkin Ortam Erişim Protokolü
}

\author{
Muhammed Enes Bayrakdar \\ Düzce Üniversitesi, Teknoloji Fakültesi, Bilgisayar Mühendisliği Bölümü, Düzce. \\ e-posta: muhammedbayrakdar@duzce.edu.tr. ORCID ID: https://orcid.org/0000-0001-9446-0988.
}

Geliş Tarihi: 02.11.2018 ; Kabul Tarihi: 06.03.2019

Öz

Anahtar kelimeler Sualtı,

Algılayıcı ağlar, Aloha, Ortam erişim.

\begin{abstract}
Sualtı algılayıcı ağlar; okyanusta veri toplama, kirlilik izleme, okyanus örneklemesi gibi çok çeşitli uygulamalarla hızla gelişen bir araştırma alanıdır. En çok araştırılan alanlardan biri, birçok uygulamanın temelini oluşturan sualtı algılayıcı ağların kapsama alanıdır. Kapsama alanı genellikle bir ağın algılayıcı tarafından ne kadar etkin izlendiği ile ilgilidir. Su kirliliği başta olmak üzere, okyanus veya deniz bölgesinde ortaya çıkan başlıca problemler vardır. Sualtı kirliliği genel olarak asitleşmeye, plastik kalıntılara ve toksinlere sebep olmaktadır. Günümüzde bu kirliliğin belirlenmesi, insan gözetimli izleme süreci ile gerçekleştirilmektedir. Bu sebeple, kirliliğin oluşumunu tanımlamak için otomatik ve akıllı izleme sistemine intiyaç duyulmaktadır. Önerdiğimiz benzetim modeli, su altındaki kirliliğin oluşumunu tanımlayan ve alarm veren akıllı algılayıcı tabanlı izleme sistemini tanımlamaktadır. Benzetim modelini tasarladığımız sistemin, maliyet açısından verimli olması için ortam erişim protokolü olarak Aloha seçilmiştir. Sistemin verimliliği benzetim modeli ile test edilerek mevcut insan gözetimi içeren izleme sürecinden daha kararlı, düşük maliyetli ve yönetilebilir olduğu gösterilmiştir. Algılayıcı ağ yükü 0 ile 6 arasında değiştiğinde, en yüksek başarım oranı 0,36 olarak ağ yükü 1 olduğunda elde edilmektedir. Gecikme değeri $0,14 \mathrm{~ms}$ ile $0,16 \mathrm{~ms}$ arasına yakın değerlerde değişirken, en düşük gecikme $0,15 \mathrm{~ms}$ olarak benzetim süresinin ortalarında elde edilmektedir.
\end{abstract}

\section{Aloha based Cost Effective Medium Access Protocol in Underwater Wireless Sensor Networks}

\author{
Keywords \\ Underwater, \\ Sensor networks, \\ Aloha,
}

Medium Access.

\begin{abstract}
Underwater sensor networks; it is a rapidly developing area of research with a wide range of applications such as data collection in ocean, pollution monitoring and ocean sampling. One of the most researched areas is the coverage of underwater sensor networks, which are the basis of many applications. The coverage is usually related to how effectively a network is monitored by the sensor. There are major problems in the ocean or marine region, especially in water pollution. Underwater pollution generally causes acidification, plastic residues and toxins. Today, the determination of this pollution is carried out through a human surveillance monitoring process. Therefore, there is a need for an automatic and intelligent monitoring system to identify the formation of pollution. The proposed simulation model defines the intelligent sensor-based monitoring system that identifies and alarms the formation of underwater pollution. Aloha was chosen as the medium access protocol for the costeffective system in which we designed the simulation model. The efficiency of the system has been shown to be more stable, cost-effective and manageable than the monitoring process involving the existing human surveillance by testing with the simulation model. When the sensor network load increases from 0 to 6 , the highest performance ratio is obtained as 0.36 when the network load is 1 . The delay value changes between $0.14 \mathrm{~ms}$ and $0.16 \mathrm{~ms}$, while the lowest delay is acquired as $0.15 \mathrm{~ms}$ in the middle of simulation duration.
\end{abstract}




\section{Giriş}

1990 'ların ortasından bu yana, karasal kablosuz algılayıcı ağı hızla gelişmektedir (Yang vd. 2009, Chao 2016). Ancak, sınırlı bant genişliği ve geniş yayılma gecikmeleri gibi sualtı akustik kanalının belirli özellikleriyle sınırlanan sualtı algılayıcı ağının gelişimi, karasal kablosuz algılayıcı ağının okyanus uygulamasında uzantısı, karasal kablosuz algılayıcıların gerisinde kalmaktadır (Lee vd. 2011, Park vd. 2009). Mevcut sualtı algılayıcı şebekesinin ortam erişim kontrol metodu, verimliliği nispeten düşük olan çarpışma kaçınmalı çoklu erişim protokolüne ve pratik ihtiyaçları karşılamak için güvenilir olan Aloha protokolüne dayanmaktadır (Park 2009, Li vd. 2012). Ayrıca, ağır ağ yükü durumunda paket çarpışması daha da artarak ağ performansında daha fazla güç tüketimi ve bozulma ortaya çıkarmaktadır (Basagni vd. 2014, Rachman vd. 2012). Dahası, okyanus tabanlı cihazlar genellikle batarya ile çalıştığından dolayı tek düğümün güç tüketimi tüm ağın ömrü ile doğrudan ilgilidir (Yashwanth ve Sujatha 2016). Bu sebeple, düşük güç düğümü mimarisi ve düşük güç ortam erişim kontrol protokolünün tasarımı son araştırmalardaki en önemli noktadır (Goyal vd. 2016, Erol ve Aktug 2008). Algılayıcı ortam erişim kontrol protokolüne dayalı senkron bir ortam erişim tekniği protokolü algılayıcı ağlar için standart olarak önerilmektedir (Byeon vd. 2008, Guangzhong ve Zhibin 2010). Güç tüketimini azaltmak için "uyku-uyanık" modda çalışır ve bilgi çarpışmasını önlemek için her düğüm arasında yayılım senkronizasyonu sağlamaktadır (Lazar vd. 2016). Ek olarak, güç tüketimini azaltmak için farklı ortam erişim teknikleri de önerilmektedir (Rezaei vd. 2012). Ancak, bu tekniklerde de düğümü uyandırmak için özel, ultra düşük güçlü alıcı kullanılması gerekmektedir (Erdem ve Gungor 2017).

Bununla birlikte, algılayıcı ağ düğümünün çoğu donanım mimarisi, belirli bir uygulama için genel kullanım alanına sahip değildir (Fauziya vd. 2016, Yu vd. 2009). Bu nedenle, araştırmacılar mevcut sualtı algılayıcı ağların ortam erişim teknikleri protokollerinin pratik performansını test etmek için birleşik bir platformdan yoksundurlar (Zhan vd.
2009, Wahid ve Kim 2012). Sualtı algılayıcı ağ içinde noktadan noktaya iletişimin performansını test etmek için evrensel ekipman kullanma yöntemi referans olarak önerilmişse de, bunun enerji tüketimi araştırmacıların beklediğinden biraz daha yüksek olmaktadır (Akhter vd. 2016).

Wahid ve arkadaşları, sualtı kablosuz algılayıcı ağları için bağlantı tabanlı bir yönlendirme protokolü önermişlerdir (Wahid ve Kim 2012). Önerdikleri protokolde, algılayıcı ağlarda yüksek hata oranlarıyla karşılaşılması nedeniyle güvenilirlik konusunu ele almışlardır. Bu nedenle, iletim sırasında hedef ile en güçlü bağlantıya sahip olan bir düğümü, bir sonraki yönlendirme düğümü olarak seçmektedirler. NS-2 simülatörünü kullanarak, önerdikleri protokolü lokalizasyonsuz yönlendirme protokolüyle karşılaştırmışlardır. Simülasyon sonuçları ile, önerdikleri protokolün daha fazla performans artışı gösterdiğini vurgulamaktadırlar (Wahid ve Kim 2012).

Yu ve arkadaşları, sualtı ortamları için sualtı kablosuz algılayıcı ağlarında algılayıcı lokalizasyonu tekniğini incelemişlerdir (Yu vd. 2009). Sualtı ortamlarında, radyo frekans sinyalinin aşırı sınırlı yayılma nedeniyle sualtı kullanımı için uygun olmadığını vurgulamışlardır. Bu nedenle, sualtı algılayıcı ağların akustik modemlerle oluşturulması gerekliliğini belirtmektedirler. Bu yüzden, her bir algılayıcı pozisyonunu belirlemek için yeni bir lokalizasyon algoritmasına ihtiyaç duymuşlardır. Öncelikle, karasal ortamlar için lokalizasyon tekniklerini incelemişlerdir. Daha sonra sualtı kullanımında uygun algoritmayı sunmuşlardır. Son olarak, algılayıcı düğümün iletişim aralığı, düğüm sayısı ve referans düğümün konumu arasındaki farklı koşulları kullanarak sualtı tabanlı lokalizasyon algoritmasını değerlendirmişlerdir (Yu vd. 2009).

Byeon ve arkadaşları, düşük enerji, yüksek hız ve düşük maliyet sualtı algılayıcı ağlar için bir ön koşul olduğundan, çalışmalarında genel amaçlı su geçirmez bir algılayıcı kullanarak sualtı modemi tasarlamışlardır ve uygulamışlardır (Byeon vd. 2008). Ayrıca, iki noktadan noktaya modem içeren bir su deposunda bazı deneyler yapmışlardır. 
Yaptıkları deneylere göre, 1 kbps'lik bir veri hızı ile 1 metrelik bir mesafede neredeyse hatasız iletişimin mümkün olduğunu vurgulamaktadırlar. Fakat veri hızının artmasıyla iletişim kalitesinin hızla bozulduğunu ortaya koymuşlardır (Byeon vd. 2008).

Katti ve arkadaşları, farklı algılayıcı kurulum şemalarını ve bunların kapsama alanı üzerindeki etkilerini incelemişlerdir (Katti ve Lobiyal 2016). Maksimum kapsama alanı için üçgen, ızgara ve altıgen tabanlı algılayıcı yerleştirme şemalarını karşılaştırmışlardır. Buna göre, istenilen bir kapsama alanı seviyesine ulaşmak için her bir durumda gereken algılayıcı düğümlerin sayısını hesaplamışlardır (Katti ve Lobiyal 2016).

Önerdiğimiz benzetim modeli, su altındaki kirliliğin oluşumunu tanımlayan ve alarm veren akıllı algılayıcı tabanlı izleme sistemini tanımlamaktadır. Benzetim modelini tasarladığımız sistemde maliyet açısından verimli olması ve düşük güç tüketmesi için ortam erişim protokolü olarak Aloha seçilmiştir. Yazılım radyo teknolojisi konseptine dayanan bu tasarım ve mimari, hem genelliği hem de düşük güç tüketimini sağlamak için "uyku-uyanık" modda çalışmaktadır. Benzetim modelinin tasarımı ve mimarisi için Riverbed Modeler ve Matlab yazılımlarından faydalanılmıştır (Matlab 2018). Her bir algılayıcı düğümün tasarımı, sualtı kirliliğini tespit edecek şekilde ayarlanmıştır. Sistemin verimliliği benzetim modeli ile test edilerek mevcut insan gözetimi içeren izleme sürecinden daha kararlı ve yönetilebilir olduğu gösterilmiştir. Tasarladığımız sualtı algılayıcı ağ, ortam erişim kontrol protokolü üzerinde gelecekteki çalışmalar için uygun bir donanım platformu sağlamaktadır.

\section{Materyal ve Metot}

Çalışmamızda, sualtı kablosuz algılayıcı ağlarda kirlilik kontrolü için maliyet etkin ortam erişim protokolü tasarımı ve benzetimi yapılmıştır. A yapımızın temeli ve tasarımı tamamlandıktan sonra, Riverbed Modeler yazılımı ile benzetimi yapılmıştır (Riverbed 2018). Senaryo olarak, denizlerde veya okyanuslarda belirli bir bölgenin yenilebilir balık avlama bakımından temiz olup olmadığını tespit etmek için oradaki suyun kimyasal özelliklerinin algılayıcı dügümler yardımıyla uzun süreli gözlemlenmesi düşünülmüştür.

Riverbed Modeler yazılımı; tasarım, benzetim ve veri toplama gibi çeşitli araçlar içermektedir. Riverbed Modeler ayrıca kablosuz iletişim ağlarının modellenmesini ve dağıtılmış ağ sistemlerini içeren kapsamlı bir geliştirme ortamını desteklemektedir.

Riverbed yazılımında, bir benzetim modelinin performans değerlendirmesi, ayrık olay benzetimleri aracılığıyla değerlendirilmektedir. Riverbed Modeler yazılımının kaynak kodu Proto $C$ programlama dilinde yazılmaktadır.

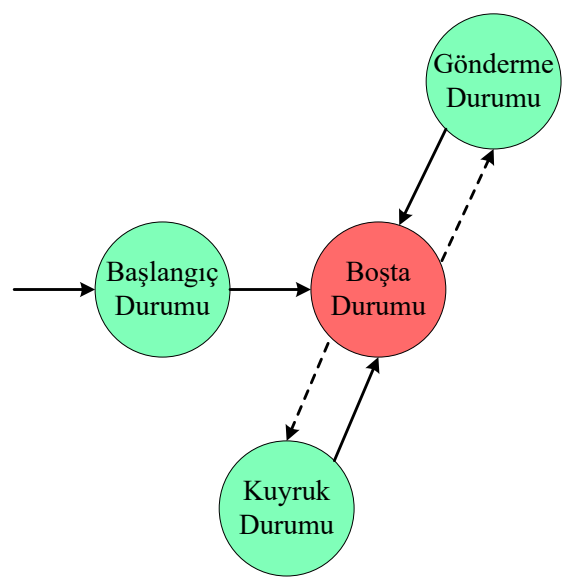

Şekil 1. Benzetim yazılımı algoritması

Şekil 1'de, benzetim yazılımında kullanılan kablosuz algılayıcı düğümlerin işlem modeli tasarlanmıştır. Riverbed benzetim yazılımı olaya dayalı olduğundan; tüm değişkenler tanımlandıktan sonra, ilk değerleri başlangıç durumda atanmaktadır. Ardından, işlem boşta duruma geçmekte ve yeni bir olayın meydana geldiğini belirten bir kesmenin gerçekleşmesini beklemektedir. Kuyruk durumunda; algılayıcı düğüm algılama işlemini gerçekleştirerek veri paketlerini kuyruğa eklemektedir. Kuyruktaki mevcut veri paketlerinin iletimi için gönderme durumuna geçilmektedir.

\subsection{Sualtı algılayıcı ağ tasarım ve benzetimi}

Şekil 2'de gösterilen sualtı algılayıcı ağ tasarımımızda, sualtına yerleştirilmiş çok sayıda algılayıcı bulunmaktadır. Algılayıcılar kendi aralarında tasarsız (ad-hoc) olarak haberleşmektedir. 
Gerektiği durumlarda da birbirleri üzerinden haberleşerek verilerini yüzey düğüme aktarmaktadırlar. Ortam erişim tekniği olarak maliyet etkin bir protokol olan Aloha tabanlı teknik kullanmaktadırlar. Sualtı algılayıcı düğümlerden gelen verileri toplamak için kullanılan bir de yüzey düğüm bulunmaktadır. Yüzey dügümün görevi, algılayıcı düğümlerden kendisine gelen verileri kıyı istasyona aktarmaktır. Kıyı istasyonun topladığı veriler, civarda bulunan herhangi bir çevrimiçi izleme merkezinden izlenmekte ve takip edilmektedir. Yüzey düğüm aynı zamanda, sualtı algılayıcı düğümlerin veri trafiğini yönlendiren bir koordinatör düğüm konumundadır.
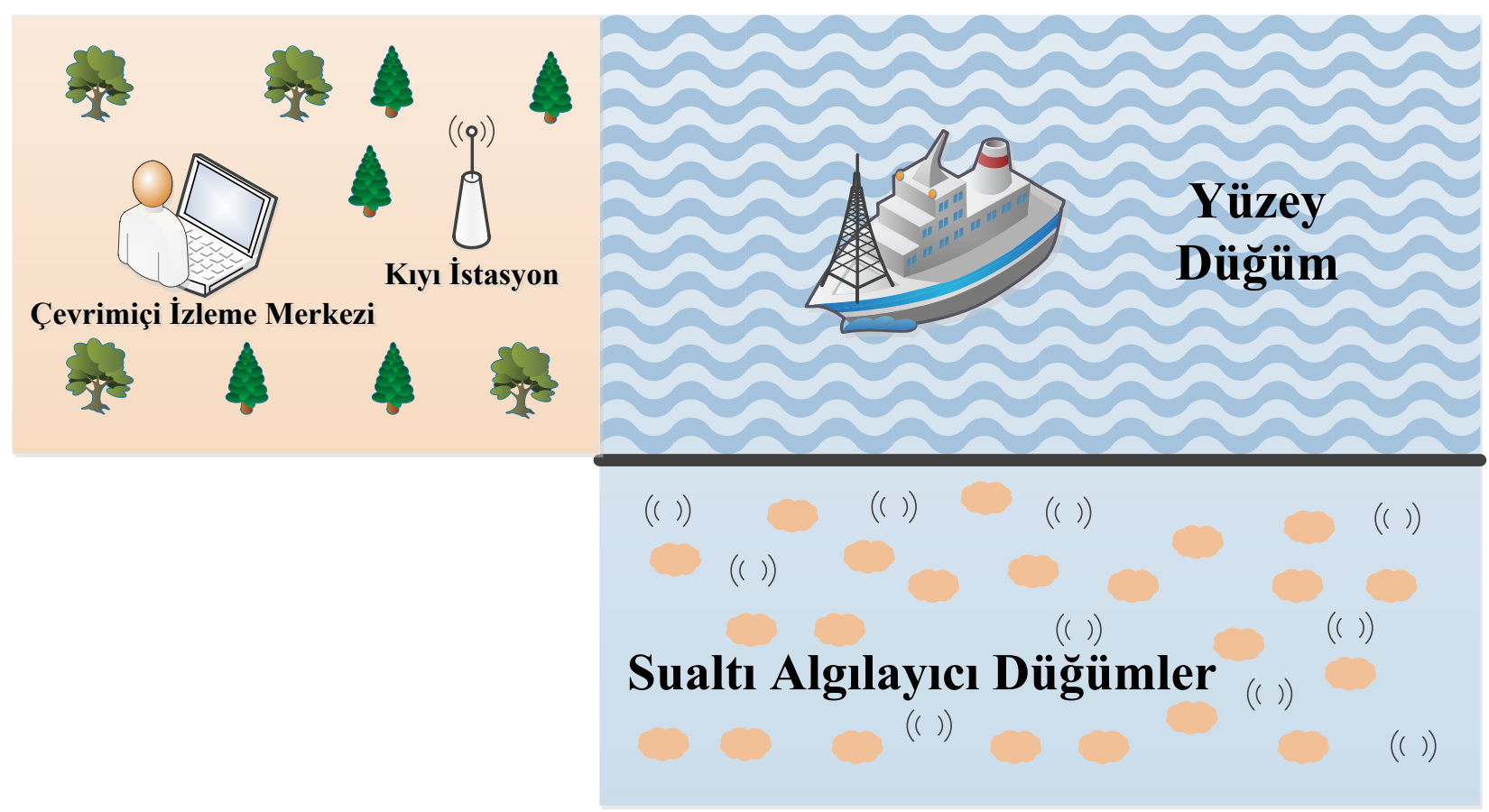

\section{Şekil 2. Sualtı algılayıcı ağ tasarımı}

Çizelge 1'de, benzetim modelimizde kullanılan algılayıcı ağ parametreleri verilmektedir.

Çizelge 1. Sualtı algılayıcı ağ benzetim parametreleri.

\begin{tabular}{lc}
\hline Parametre & Değer \\
\hline Veri iletim hızı & $10 \mathrm{Kbps}$ \\
\hline Paket boyutu & 50 byte \\
\hline Gecikme & $25 \mathrm{us}$ \\
\hline Frekans & $25 \mathrm{Khz}$ \\
\hline Benzetim süresi & $3600 \mathrm{sn}$ \\
\hline Gönderim gücü & $2 \mathrm{~mW}$ \\
\hline Alım gücü & $0,75 \mathrm{~mW}$ \\
\hline Algılayıcı düğüm sayısı & 22 \\
\hline
\end{tabular}

Sualtı algılayıcı ağlarda, enerji verimliliğini en üst düzeye çıkarabilmek için gecikmenin minimum düzeyde tutulması gerekmektedir. Sualtı ortamlar oldukça yoğun olduğu için, sinyal iletiminin paket kayıplarına maruz kalmaması için gecikme seviyesinin de mümkün olan en düşük seviyede olması gerekmektedir. Paket kaybı, aynı paketin tekrar iletilmesi gerekliliğinden dolayı büyük miktarda enerji sarfiyatına sebep olmaktadır. Bu sebeplerden dolayı, sualtı algılayııı ağlarda gecikme ve paket kayıplarının göz önünde bulundurulması oldukça önemlidir.

\subsection{Aloha tabanlı ortam erişim tekniği}

Sualtı algılayıcı ağlarda Aloha protokolünün kullanılmasının en önemli sebebi, düğümler arası rasgele yayılım gecikmesinin performans üzerinde herhangi bir olumsuz etkisinin bulunmamasıdır. Ayrıca, Aloha protokolünde herhangi bir sezme veya geri bildirim mekanizması bulunmadığından dolayı ekstra enerji tüketimi ve gecikme yaşanmamaktadır.

Slotted Aloha tekniğinde, zaman $\alpha$ paket süresine eşit veya bu süreden büyük olacak şekilde eşit dilimler uzunluğunda parçalara bölünmektedir. Her 
bir algılayıcı düğüm, sadece zaman diliminin başlangıcında paket gönderimi yapabilmektedir. Eğer bir düğümün zaman diliminin başlangıcı dışında hazır paketi olur ise, bir sonraki zaman diliminin başlangııına kadar bekleme yapmaktadır.

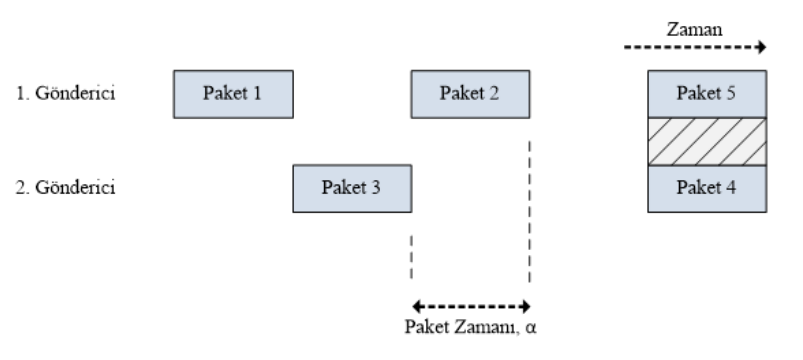

Şekil 3. Slotted Aloha tekniğinde örnek paket iletimi

Şekil 3'te; Paket 1, Paket 2 ve Paket 3 çarpışmasız bir şekilde gönderilmekte iken, Paket 4 ve Paket 5 çarpışmaktadır. Bu yüzden, bu iki paketin sonraki zaman dilimlerinde tekrar gönderilmesi gerekmektedir. Slotted Aloha tekniğinde, düğümlerin tekrar gönderim yapmadan önce beklediği süre trafiğin gecikme karakteristiğini belirlemektedir. Slotted Aloha için kritik süre, kısmi çarpışmalar meydana gelmediği için sadece bir paket zamanıdır. Kritik süre boyunca başka hiçbir gönderimde bulunulmama olasılığı; $G$ ortalama yük olmak üzere $\mathrm{e}^{-G}$ olmaktadır. $S$ başarım oranı olmak üzere;

$$
\mathrm{S}=\mathrm{G} * \mathrm{e}^{-\mathrm{G}}
$$

ifadesiyle Slotted Aloha protokolünün başarımı oranı elde edilmektedir. Başarım oranı en fazla yükün 1 olduğu durumda elde edilmektedir ve 0,36 civarında olmaktadır.

Slotted Aloha tekniğinin gecikme ifadesi D; tp yayılım gecikmesi olmak üzere;

$$
\mathrm{D}=\mathrm{tp}+\left(\mathrm{e}^{\mathrm{G}}-1\right)
$$

olarak bulunmaktadır. Ortalama gecikme sualtı algılayıcı ağımız için ortalama olarak 0,16 ms civarında olmaktadır.

Slotted Aloha tekniğinin sualtı algılayıcı ağlar için olumlu yönleri şu şekildedir: (i) Zaman dilimlerinin dışında paket iletimi başlatılmadığı için, kısmi çarpışmalar engellenmiş olur. (ii) Çok fazla paket iletimi yapıldığı durumlarda, sabit tahsis ilkesine göre çalışan sistemlerden daha verimlidir. (iii) Geri bildirim sistemine sahip olduğu için, paketlerin başarılı bir şekilde iletildiğinden emin olunur. (iv) Sualtı algılayıcı ağa yeni algılayıcıların eklenmesi ve çıkarılması kolaydır.

\section{Bulgular}

Şekil 4'te, Slotted Aloha tekniğinin algılayıcı ağ yüküne göre başarım oranı grafiği görülmektedir.

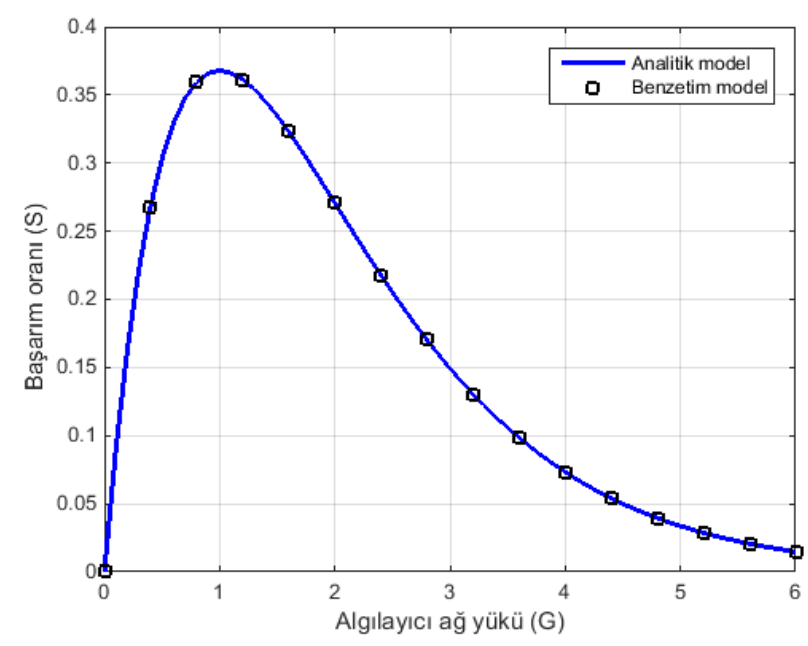

Şekil 4. Slotted Aloha tekniğinin başarım oranı

Grafik incelendiğinde, algılayıcı ağ yükünün 0 ile 6 arasında değiştiği görülmektedir. En yüksek başarım oranı da 0,36 olarak ağ yükü 1 olduğunda elde edilmektedir. Ayrıca, matematiksel model sonuçlarının benzetim modeli sonuçları ile birebir örtüştüğü açıkça görülmektedir.

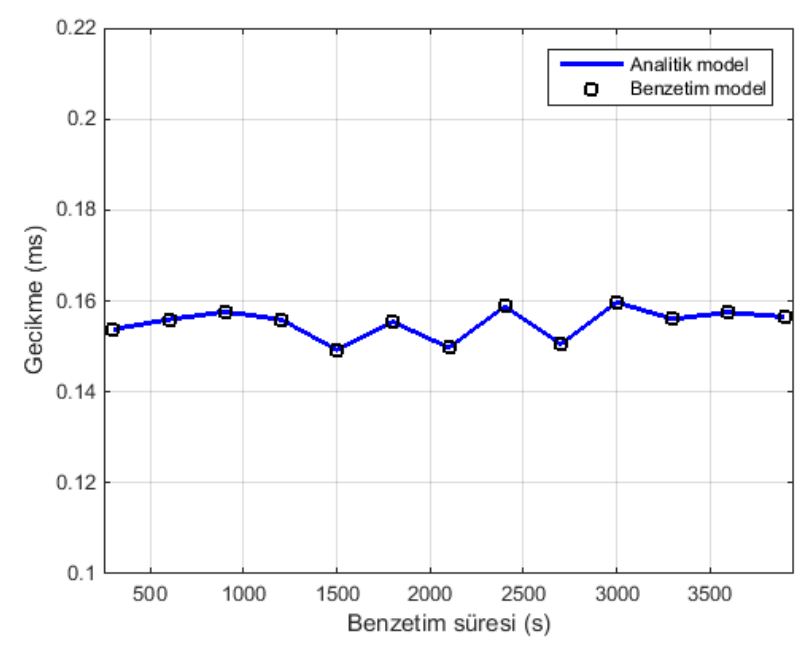

Şekil 5. Slotted Aloha tekniğinin gecikme analizi

Şekil 5'te, Slotted Aloha tekniğinin gecikme analizi grafiği görülmektedir. Grafik incelendiğinde, benzetim süresi boyunca gecikme değerinin 0,14 ile 
0,16 arasında değiştiği görülmektedir. En düşük gecikme 0,15 olarak benzetim süresinin ortalarında elde edilmektedir. Ayrıca, benzetim modeli sonuçlarının analitik model sonuçları ile birebir örtüştüğü net bir şekilde anlaşılmaktadır.

Kablosuz sualtı algılayıcı ağlarda; kablolu sualtı ağlarda olan kablo hattı çekme, boru döşeme, bağlantı bakımları vb. maliyetler bulunmadığı için maliyet açısından oldukça verimlidir. Kablosuz sualtı algılayıcı ağlarda, kablolu ağlarda yaşanabilecek kablo kopma sorunu ve bunun bakımı gibi maliyetler olmamaktadır. Bunun yanında, mümkün olan en düşük sayıda düğümü belirlenen sualtı konumlara en uygun şekilde yerleştirerek kablosuz algılayıcı düğüm sayısından da maliyet tasarrufu sağlanmaktadır.

Şekil 4 ve Şekil 5 dikkatli bir şekilde incelendiğinde, benzetim model ve analitik model sonuçlarının çok yakın olması, sualtı algılayıcı ağ tabanlı maliyet ve gecikme verimli ortam erişim tekniğimizin geçerliliğini ortaya koymaktadır. Elde edilen bulgular, benzetim modelini geliştirdiğimiz maliyet etkin sualtı algılayıcı ağ modelinin hedeflenen özellikleri sağladığı için gerçek hayattaki deniz, göl gibi sualtı ortamlarda da kullanılabileceğini açık bir şekilde kanıtlamaktadır.

\section{Tartışma ve Sonuç}

Önerdiğimiz benzetim modeli, su altındaki kirliliğin oluşumunu tanımlayan ve alarm veren akıllı algılayıcı tabanlı izleme sistemini tanımlamaktadır. Benzetim modelini tasarladığımız sistemde maliyet açısından verimli olması için ortam erişim protokolü olarak Aloha seçilmiştir. Sistemin verimliliği benzetim modeli ile test edilerek mevcut insan gözetimi içeren izleme sürecinden daha kararlı ve yönetilebilir olduğu gösterilmiştir.

Gelecek çalışmalarda, izleme sistemi ile ilgili olarak yaşanabilecek farklı sorunlara çözüm niteliğinde çalışmalar gerçekleştirilebilir. Sualtı kirliliği izleme ve kirlilik kontrol sistemleri uygulama olarak günümüzde kullanılmadığı için, tasarlanan sistemler benzetim modelleri üzerinde test edilerek sonuçlar gözlemlenebilir.

\section{Kaynaklar}

Akhter, A., Uddin, M. A., Abir, M. A. I. and Islam M. M., 2016. Noise aware level based routing protocol for underwater sensor networks. International Workshop on Computational Intelligence, Dhaka, 169-174.

Basagni, S., Bölöni, L., Gjanci, P., Petrioli, C., Phillips, C. A. and Turgut, D., 2014. Maximizing the value of sensed information in underwater wireless sensor networks via an autonomous underwater vehicle. IEEE INFOCOM - IEEE Conference on Computer Communications, Toronto, ON, 988-996.

Byeon, M., Kim, B., Jeon, J. and Park, S., 2008. Design and implementation of high-speed communication modem using ultrasonic sensors for underwater sensor networks. OCEANS Conference, Quebec City, QC, 1-4.

Chao, Y., 2016. Autonomous underwater vehicles and sensors powered by ocean thermal energy. OCEANS Conference, Shanghai, 1-4.

Erdem, H. E. and Gungor, V. C., 2017. Lifetime analysis of energy harvesting underwater wireless sensor nodes. 25th Signal Processing and Communications Applications Conference, Antalya, 1-4.

Erol, M. and Oktug, S., 2008. A localization and routing framework for mobile underwater sensor networks. IEEE INFOCOM Workshops, Phoenix, AZ, 1-3.

Fauziya, F., Agrawal, M. and Lall, B., 2016. Channel capacity of a Vector Sensor based underwater communications system. OCEANS MTS / IEEE Conference, Monterey, CA, 1-5.

Goyal, N., Dave, M. and Verma, A. K., 2016. Congestion control and load balancing for cluster based underwater wireless sensor networks. Fourth International Conference on Parallel, Distributed and Grid Computing, Waknaghat, 462-467.

Guangzhong, L. and Zhibin, L., 2010. Depth-Based Multihop Routing protocol for Underwater Sensor Network. The 2nd International Conference on Industrial Mechatronics and Automation, Wuhan, 268-270. 
Katti, A. and Lobiyal, D. K., 2016. Sensor node deployment and coverage prediction for underwater sensor networks. 3rd International Conference on Computing for Sustainable Global Development, New Delhi, 3018-3022.

Lazar, I., Ghilezan, A. and Hnatiuc, M., 2016. Development of underwater sensor unit for studying marine life. IEEE 22nd International Symposium for Design and Technology in Electronic Packaging, Oradea, 82-85.

Lee, T. J., Han, M. S., Han, J. W., Shin, S. J., Kim, K. M., Chun, S. Y. and Son, K., 2011. A Study on the Low Power Communication for Underwater Sensor Network. IFIP 9th International Conference on Embedded and Ubiquitous Computing, Melbourne, VIC, 420-423.

Li, S., Wang, W. and Zhang, J., 2012. Efficient deployment surface area for underwater wireless sensor networks. IEEE 2nd International Conference on Cloud Computing and Intelligence Systems, Hangzhou, 1083-1086.

Park, S., 2009. An efficient transmission scheme for underwater sensor networks. OCEANS - EUROPE Conference, Bremen, 1-3.

Park, S., Jo, B. and Han, D., 2009. An efficient mac protocol for data collection in underwater wireless sensor networks. MILCOM - IEEE Military Communications Conference, Boston, MA, 1-5.

Rachman, R., Laksana, E. P., Putra, D. S. and Sari, R. F., 2012. Energy Consumption at the Node in Underwater Wireless Sensor Network (UWSNs). Sixth UKSim/AMSS European Symposium on Computer Modeling and Simulation, Valetta, 418-423.

Rezaei, H. F., Kruger, A. and Just, C., 2012. An energy harvesting scheme for underwater sensor applications. IEEE International Conference on Electro/Information Technology, Indianapolis, IN, 1-4.

Wahid, A. and Kim, D., 2012. Connectivity-based routing protocol for underwater wireless sensor networks. International Conference on ICT Convergence, Jeju Island, 589-590.

Yang, Y., Xiaomin, Z., Bo, P. and Yujing, F., 2009. Design of sensor nodes in underwater sensor networks. 4th
IEEE Conference on Industrial Electronics and Applications, Xi'an, 3978-3982.

Yashwanth, N. and Sujatha, B. R., 2016. Wireless sensor node localization in underwater environment. International Conference on Electrical, Electronics, Communication, Computer and Optimization Techniques, Mysuru, 339-344.

Yu, C. H., Lee, K. H., Moon H. P., Choi, J. W. and Seo, Y. B., 2009. Sensor localization algorithms in underwater wireless sensor networks. ICCAS-SICE Conference, Fukuoka, 1760-1764.

Zhan, A., Chen, G. and Wang, W., 2009. Utilizing Automatic Underwater Vehicles to Prolong the Lifetime of Underwater Sensor Networks. Proceedings of 18th International Conference on Computer Communications and Networks, San Francisco, CA, 1-6.

\section{internet kaynakları}

1-Riverbed Modeler, https://www.riverbed.com/gb/, (31.10.2018)

2-Matlab Software, https://ww2.mathworks.cn/en/ (31.10.2018). 